\title{
Nomenclature to describe the transition from multiserial to uniserial chamber arrangement in benthic foraminifera
}

\author{
MICHAEL A. KAMINSKI ${ }^{1, *}$, CLAUDIA G. CETEAN ${ }^{2,3}$ \& JAROSŁAW TYSZKA ${ }^{3}$ \\ ${ }^{1}$ Department of Earth Sciences, University College London, London WC1E 6BT, UK (Current address: \\ Earth Sciences Department, King Fahd University of Petroleum \& Minerals, Dhahran, 31261, Saudi Arabia). \\ ${ }^{2}$ Department of Palaeontology, Natural History Museum Cromwell Road, London SW7 5BD, UK. \\ ${ }^{3}$ Polish Academy of Sciences, Institute of Geological Sciences Cracow Research Centre, ul. Senacka 1, 31-002, \\ Kraków, Poland. \\ "Corresponding author (e-mail: kaminski@kfupm.edu.sa)
}

\begin{abstract}
We define terms used to describe the transition from a trochospiral, multiserial or biserial chamber arrangement to a uniserial chamber arrangement in benthic foraminifera. The morphological transition from a trocho-, multi- or biserial to a uniserial chamber arrangement may be abrupt, or form a morphological progression through transitional stages defined as 'loosely biserial', 'lax-uniserial' and, finally, 'loosely uniserial'. The precise meanings of the intermediate stages ending in uniseriality are defined here by means of examples using foraminiferal models. We introduce the new terms 'Cryptobiserial', 'Cryptotriserial' and 'Cryptotrochospiral' to describe the chamber arrangement in genera with uniserial stages that preserve the sense of coiling of the previous trochospiral, triserial or biserial stages. J. Micropalaeontol. 30(1): 7-10, May 2011.
\end{abstract}

KEYWORDS: foraminifera, morphology, ontogeny, chamber arrangement

\section{INTRODUCTION}

The transition from a multiserial to a biserial to a uniserial chamber arrangement is seldom abrupt or straightforward among benthic foraminifera, but is often characterized by intermediate stages. Such foraminiferal morphologies are transitional biformed, gradually changing their chamber arrangement during ontogeny from biserial to uniserial (see Hottinger, 2006). In the literature a number of loosely defined terms can be found to describe the transition to uniseriality, such as 'loosely biserial', 'a tendency to become uniserial' or 'irregularly uniserial'. However, these terms themselves are not used consistently and are not found defined in Hottinger's (2006) popular glossary of terms used in foraminiferal research.

As part of an effort to revise and update the descriptions of the agglutinated foraminiferal genera, we believe it is useful to precisely define the terms used to describe the transitional or intermediate stages between a multiserial or biserial chamber arrangement and uniserial growth, as so many of the agglutinated genera exhibit such behaviour. As Hottinger (2006) states in the introduction to his glossary: 'The alternating arrangement of the shell cavities is a very fundamental and widespread pattern of the foraminiferal architecture'. The biserial chamber growth pattern is known mainly from the class Rotaliata (Mikhalevich, 2000, 2005; Mikhalevich \& Debenay, 2001), which possess multilocular tests with low (brevithalamous), often globular, chambers and agglutinated or calcareous walls. This chamber arrangement is distinct in both benthic and planktonic habitats. Surprisingly, the only documented benthic-planktonic (tychopelagic) taxon is also biserial (Darling et al., 2009). Therefore, the purpose of this paper is to properly define these morphological terms to ensure that their use is consistent and well understood by foraminiferal researchers.

\section{TERMS USED TO DENOTE THE TRANSITION FROM A BISERIAL TO A UNISERIAL CHAMBER ARRANGEMENT}

Examples of the transitional stages between a biserial and uniserial chamber arrangement were generated using the moving reference model described by Łabaj et al. (2003) and by Tyszka \& Topa (2005). This model accurately produces simulated foraminiferal morphologies that can be found in nature. Figure 1 illustrates the transition from biseriality to uniseriality and the intermediate stages are defined below.

\section{Biserial}

A trochospiral chamber arrangement with about $180^{\circ}$ between consecutive chambers, thus producing two rows of chambers (Hottinger, 2006). In other words, it is an alternating chamber arrangement that creates two series of chambers. This latter definition neglects the term 'trochospiral arrangement' because the biseriality might be generated without a helicoidal chamber pattern, i.e. directly from a planispiral arrangement (see Tyszka $\&$ Topa, 2005). In true biserial forms (Figs 1.1, 1.2) the chambers comprising each row share a common horizontal or oblique suture between them. Furthermore, two series of rows create a common 'zigzag' suture, which separates both series from each other.

\section{Loosely biserial}

Chambers are arranged in two alternating rows, but the chambers within a row barely make contact with one other (Figs 1.3, 1.6, 1.7). In lateral view, the sutures separating the terminal chambers extend obliquely from one side of the test to the other. They form an extended 'zigzag' suture, nearly lacking any horizontal sutures between chambers sharing the same series. 


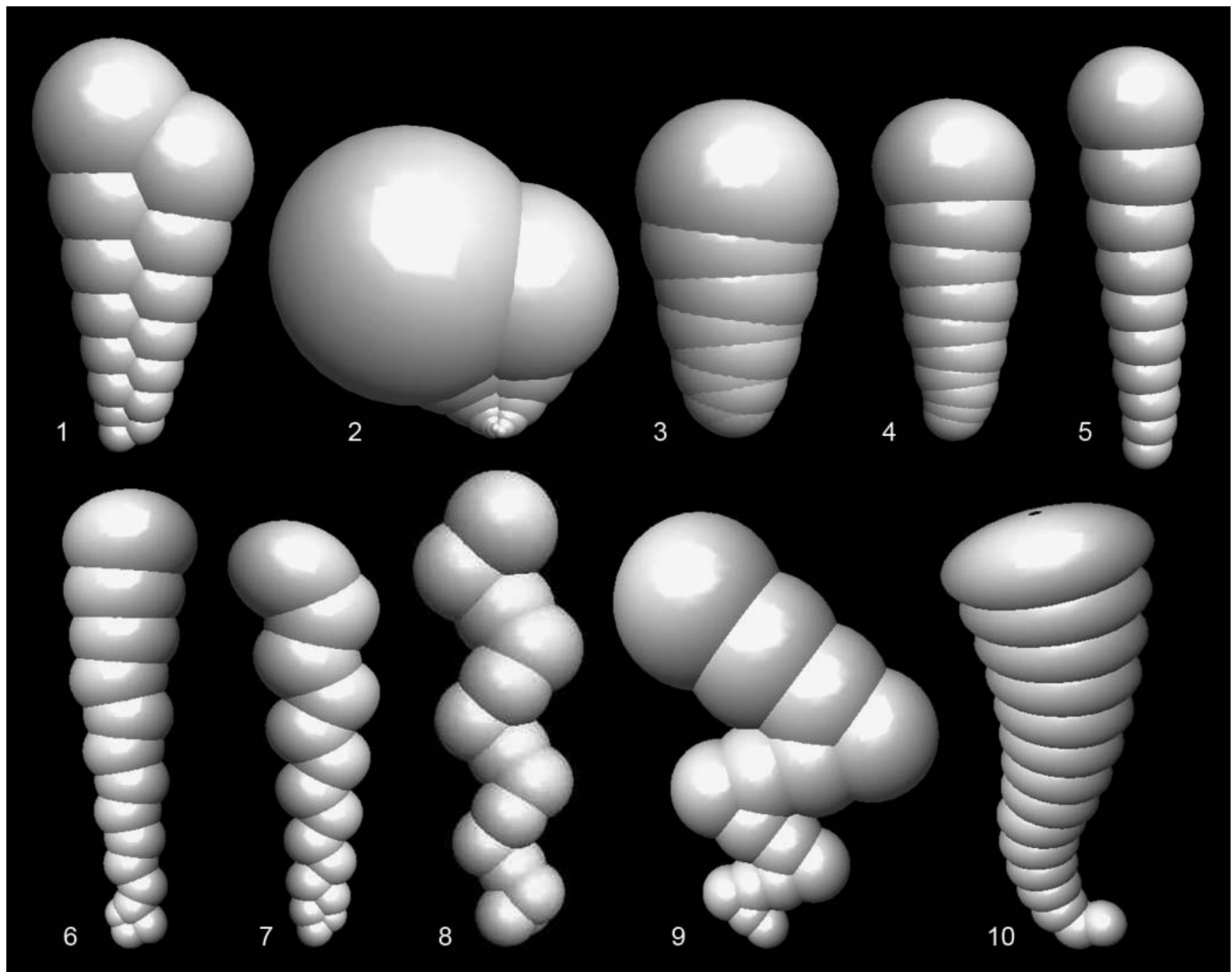

Fig. 1. Foraminiferal models illustrating the transition from biseriality to uniseriality (modified from Labaj et al., 2003). 1-2, biserial; 3, loosely biserial to lax-uniserial; $\mathbf{4}$, lax-uniserial to uniserial; $\mathbf{5}$, uniserial; $\mathbf{6}$, planispiral to loosely biserial to lax-uniserial to uniserial; $\mathbf{7}$, biserial to loosely biserial to lax-uniserial; $\mathbf{8}$, alternating uniserial with a twisted aspect; 9, alternating uniserial with a zig-zag pattern; 10, loosely uniserial.

\section{Lax-uniserial}

The chamber arrangement is truly intermediate between biserial and uniserial, such that the ultimate chamber is only in contact with the penultimate chamber (Figs 1.3, 1.4, 1.6, 1.7). The chambers are cuneate and alternate in position and the sutures between chambers are oblique. The centre points of the chambers still preserve a biserial arrangement. The term was introduced by Neagu \& Neagu (1995) to describe the genera Hagimashella and Bicazammina. The genus Eobigenerina described by Cetean et al. (2008) has a lax-uniserial stage between the initial biserial stage and the terminal uniserial stage. Loeblich \& Tappan (1987) described this type of coiling as 'alternating in a loose biserial' in the case of Haeuslerella.

\section{Alternating uniserial}

The axis of growth has a zigzag form, but each segment (or rectilinear portion) of the zigzag consists of more than two chambers (Figs 1.8, 1.9). Where the growth axis shifts direction, chambers are cuneate and sutures are oblique. In the rectilinear segments, sutures are orthogonal to the growth axis. This term was introduced by Łabaj et al. (2003) to describe this shape based on models of foraminiferal architecture. This alternating uniserial architecture is observed in the species Ammobaculites pauperculus Zheng, 2001, which was described as 'curved and twisted' in the rectilinear portion (Zheng \& Fu, 2001). In this species each segment of the zigzag consists of 3-4 chambers.

\section{Loosely uniserial}

Chambers are arranged in a single row along a straight or slightly meandering axis (Fig. 1.10), but sutures between chambers are not necessarily orthogonal to the growth axis. In loosely uniserial forms, chambers can be chaotic and irregular, as in the genus Subreophax.

\section{Uniserial}

Chambers arranged in a single row (Hottinger, 2006). The axis or growth is rectilinear and sutures between chambers are horizontal or orthogonal to the growth axis (Fig. 1.5). If the 

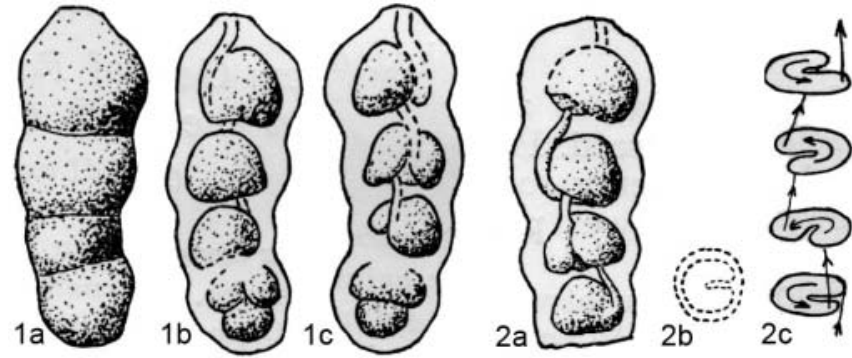

Fig. 2. Drawings of the genus Pseudoreophax Geroch, 1961, illustrating the cryptotrochospiral chamber arrangement of the pseudouniserial portion of the test. Coiling is initially trochospiral (as seen in figs 1b, 1c of a specimen drawn in immersion), but the intercameral connections viewed in immersion (figs $2 \mathrm{a}, 2 \mathrm{c}$ ) reveal that the pseudouniserial chambers continue to rotate from one chamber to the next, thus preserving the trochospiral coiling (modified from Geroch, 1961).

growth axis is gently curved, the sutures may be oblique. The term uniserial describes the nature of the chamber arrangement from an external view; however, dissection of some foraminifera (or observations of the shape of the chamber interiors viewed in immersion) reveal that some terminally 'uniserial' forms in fact preserve the sense of coiling of the earlier part of the test. In such cases new concise terms are needed to accurately describe the nature of the uniserial part, which typically displays rotation of chambers. These terms are introduced below.

\section{Pseudouniserial}

Chambers are externally arranged in a single row and sutures between chambers are horizontal or subhorizontal. Loeblich \& Tappan (1985) used the term to describe their genus Gyrovalvulina, which has chambers arranged terminally in a loose spiral. Chambers gradually become broader and fewer per whorl, until each chamber extends more than half the distance around the test but is not completely uniserial. The spiralling nature of the terminal chamber is illustrated by the alternating position of the apertural tooth, which projects obliquely within the chamber cavity. Pseudouniserial coiling may be characterized further as cryptobiserial, cryptotriserial, etc. depending upon the angle successive chambers make with respect to previous chambers.

\section{Cryptobiserial, cryptotriserial, cryptotrochospiral, etc. (new terms)}

Chambers are externally arranged in a single row and sutures between chambers are horizontal, but the internal structure of the test reveals that a sense of coiling still exists, for example the position of the aperture or internal connections alternates between chambers, or twists from one chamber to the next. Chambers within the uniserial part typically rotate with respect to one another. This feature was first pointed out by Geroch (1961) with respect to his genus Pseudoreophax (Fig. 2). Loeblich \& Tappan (1987) used the term 'pseudobiserial' to describe this mode of coiling, though we prefer the term 'cryptobiserial'. In their description of the genus Clavulina, which is initially triserial and externally terminally uniserial, Loeblich \& Tappan (1987) observed that successive toothplates in the uniserial part of the type species are orientated $120^{\circ}$ apart, reflecting the original triseriality of the test. In general, the spiralling nature of cryptobiserial or cryptotriserial forms can be determined only by observing the internal structure of the test or asymmetries of the aperture, including the orientation of the apertural tooth in successive chambers, if present.

\section{DISCUSSION AND CONCLUSIONS}

In addition to the simple transition from biserial to uniserial, more complex trimorphic chamber arrangements are found that also include the transition from biserial to uniserial patterns. The most distinctive are triserial-biserial-and-uniserial genera, such as the agglutinated Spiroplectinata or calcareous Uvigerina, or planispiral-biserial-uniserial tests, as in the genus Plectoeratidus recently described by Kaminski et al. (2009). These ontogenetic transitions, as well as the results of foraminiferal modelling, show that biseriality is morphogenetically related to uniseriality and planispirality (see Tyszka, 2006).

The morphogenetic reason for the transition from a biserial to a uniserial chamber pattern seems to be connected to the transition between apertures, which are responsible for the change in chamber growth (see Mikhalevich \& Debenay, 2001). This true transition is usually (but not necessarily) associated with the change from basal apertures in the biserial arrangement, through areal apertures, to terminal apertures in the wholly uniserial chamber arrangement.

As mentioned previously, the biserial chamber arrangement is known mainly from the class Rotaliata (sensu Mikhalevich). Within this class, the calcareous Rotaliida sensu lato (Bowser et al., 2006), with simple biserial and coiled biserial morphotypes, form a monophyletic clade based on molecular phylogenetic evidence, including the closely related Bolivina and Brizalina, as well as cassidulinids (Schweizer et al., 2008). The same clade includes the genus Uvigerina, which shows transitions from a triserial through loosely triserial, then biserial and, finally, to a lax-uniserial chamber arrangement. These results once again show that molecular phylogeny is closely linked with morphological evolutionary trends.

\section{ACKNOWLEGEMENTS}

The revision of agglutinated foraminiferal genera is supported by a consortium of petroleum companies and micropalaeontological consultancies (BP, Chevron, Saudi Aramco, Shell, Total, PDVSA, RPS Energy, Fugro Robertson Ltd., Petrobras and Petronas). The authors thank Alan Lord and Miroslav Bubík for kindly reviewing a draft of this paper.

\section{Manuscript received 26 August 2010 Manuscript accepted 9 November 2010}

Scientific editing by Michal Kucera

\section{REFERENCES}

Bowser, S.S., Habura, A. \& Pawłowski, J. 2006. Molecular evolution of foraminifera. In: Katz, L. \& Bhattacharya, D. (Eds), Genomics and evolution of microbial eukaryotes. Oxford University Press, New York, 78-93.

Cetean, C.G., Setoyama, E., Kaminski, M.A., Neagu, T., Bubík, M., Filipescu, S. \& Tyszka, J. 2008. Eobigenerina n. gen., a cosmopolitan deep-water agglutinated foraminifer, and remarks on species formerly assigned to the genera Pseodobolivina and Bigenerina. In: Filipescu, S. \& Kaminski, M.A. (Eds), Eighth International Workshop on Agglutinated Foraminifera, Abstract volume. Grzybowski Foundation Special Publication, 14: 6-7. 
Darling, K.F., Thomas, E., Kasemann, S.A., Seears, H.A., Smart, C.W. \& Wade, C.M. 2009. Surviving mass extinction by bridging the benthic/planktic divide. Proceedings of the National Academy of Sciences, USA, 106: 12629-12633.

Geroch, S. 1961. Pseudoreophax nowy rodzaj otwornic z dolnej Kredy Karpat fliszowych [Pseudoreophax, a new genus of foraminifera from the lower Cretaceous of the Flysch Carpathians]. Rocznik Polskiego Towarzystwa Geologicznego, 31: 159-161.

Hottinger, L. 2006. Illustrated glossary of terms used in foraminiferal research. Carnets de Geologie, Memoir 2. Available online at: http:// paleopolis.rediris.es/cg/CG2006_M02/index.html

Kaminski, M.A., Setoyama, E. \& Tyszka, J. 2009. Plectoeratidus subarcticus, n. gen., n. sp., a new agglutinated foraminifer from the Upper Cretaceous of the western Barents Sea. Annales Societatis Geologorum Poloniae, 79: 141-146.

Łabaj, P., Topa, P., Tyszka, J. \& Alda, W. 2003. 2D and 3D models of the growth of foraminiferal shells. Lecture Notes in Computer Science, 2657: 669-678.

Loeblich, A.R. Jr \& Tappan, H. 1985. Some new and redefined genera and families of agglutinated foraminifera II. Journal of Foraminiferal Research, 15: 175-217.

Loeblich, A.R. Jr \& Tappan, H. 1987. Foraminiferal Genera and their Classification. Van Nostrand Reinhold, New York, 970pp.

Mikhalevich, V.I. 2000. The phylum Foraminifera d'Orbigny, 1826 Foraminifers. In: Alimov, A.F. (Ed.), Protista: Manual on Zoology,
533-623. Nauka Publishers, St. Petersburg (2000) [in Russian, with English summary, 611-616].

Mikhalevich, V.I. 2005. Polymerization and oligomerization in foraminiferal evolution. Studia Geologica Polonica, 124: 117-141.

Mikhalevich, V.I. \& Debenay, J.-P. 2001. The main morphological trends in the development of the foraminiferal aperture and their taxonomic significance. Journal of Micropaleontology, 20: 13-28.

Neagu, T. \& Neagu, M. 1995. Smaller agglutinated foraminifera from the acanthicum Limestone (Upper Jurassic), Eastern Carpathians, Romania. In: Kaminski, M.A., Geroch, S. \& Gasinski, M.A. (Eds), Proceedings of the Fourth International Workshop on Agglutinated Foraminifera, Kraków Poland, September 12-19, 1993. Grzybowski Foundation Special Publication, 3: 211-225.

Schweizer, M.J., Pawłowski, J., Kouwenhoven, T.J., Guiard, J. \& van der Zwaan, B. 2008. Molecular phylogeny of Rotaliida (Foraminifera) based on complete small subunit rDNA sequences. Marine Micropaleontology, 66(3-4): 233-246.

Tyszka, J. 2006. Morphospace of foraminiferal shells: results from the moving reference model. Lethaia, 39(1): 1-12.

Tyszka, J. \& Topa, P. 2005. A new approach to modelling of foraminiferal shells. Paleobiology, 31(3): 522-537.

Zheng, S.Y. \& Fu, Z.X. 2001. Fauna Sinica, Phylum Granuloreticulosa, Class Foraminiferea, Agglutinated Foraminifera. Science Press, Beijing. 